\title{
Mechanical properties enhancement while decreasing viscosity of copolyether-ester from in situ formation of star-based structures by reactive extrusion
}

\author{
A. Lucas ${ }^{\mathrm{a}}$, A. Tauleigne ${ }^{\mathrm{a}}$, F. Da Cruz Boisson ${ }^{\mathrm{b}}$, A. Crépet ${ }^{\mathrm{a}}$, A. Vanhille \\ Bergeron $^{c}$, G. Martin ${ }^{c}$, N. Garois ${ }^{c}$, P. Cassagnau ${ }^{a}$, V. Bounor-Legaréa* \\ a- Univ Lyon, Université Lyon1, CNRS UMR 5223, Ingénierie des Matériaux Polymères, F-69622, \\ LYON, France \\ b- Univ Lyon, INSA de Lyon, CNRS UMR 5223, Ingénierie des Matériaux Polymères, F-69621, LYON, \\ France \\ c- Hutchinson, Centre de Recherche, Rue Gustave Nourry - B.P. 31, 45120, Chalette-sur-Loing, \\ France \\ *Email :bounor@univ-lyon1.fr
}



Figure S1: NMR SPECTRA OF COPE, T-403 AND COPE + 10\%wt T-403 BLEND

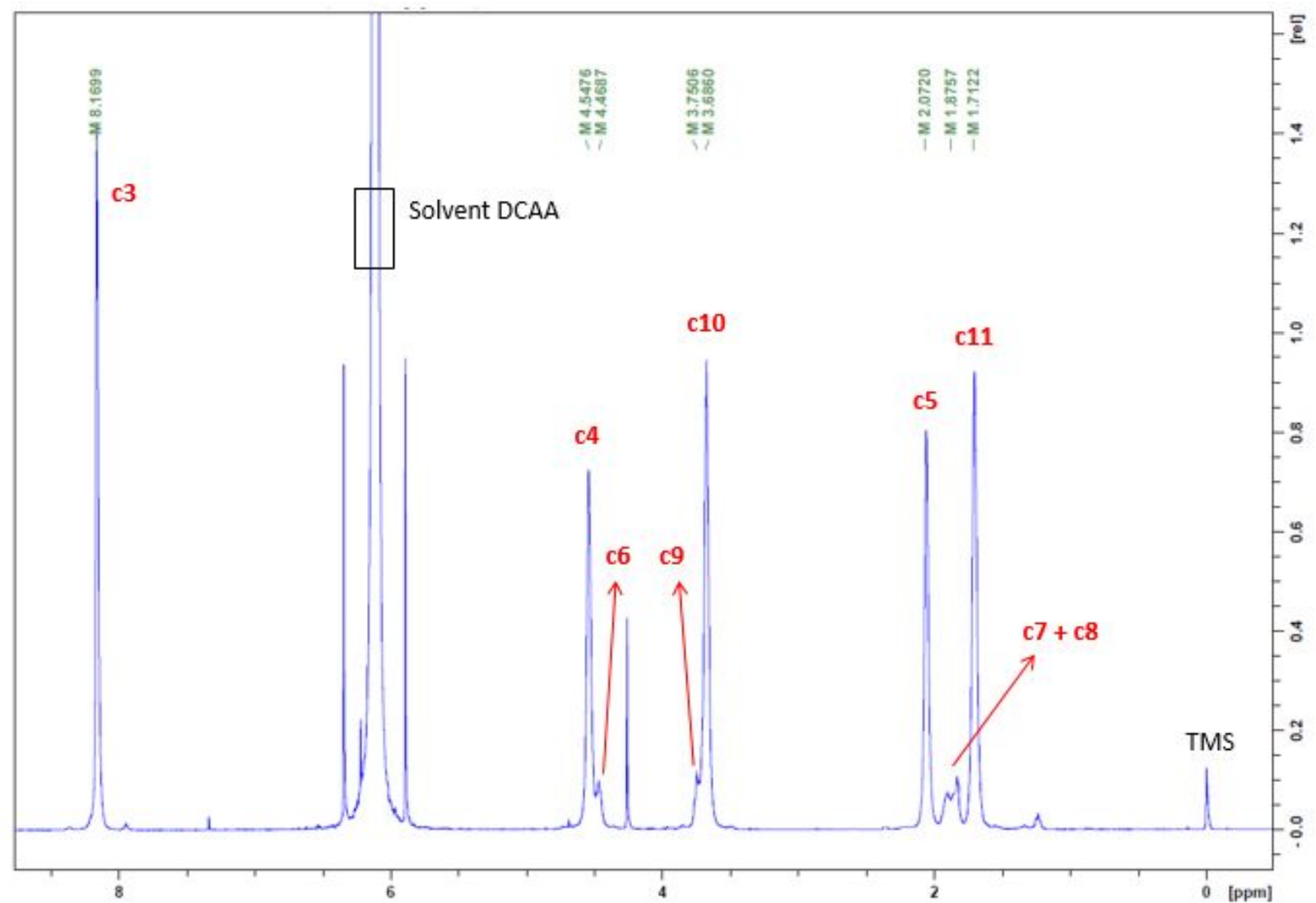

${ }^{1} \mathrm{H}$ NMR Spectrum of COPE in DCAA/CDCl $3(80: 20 \mathrm{v} / \mathrm{v})$ 


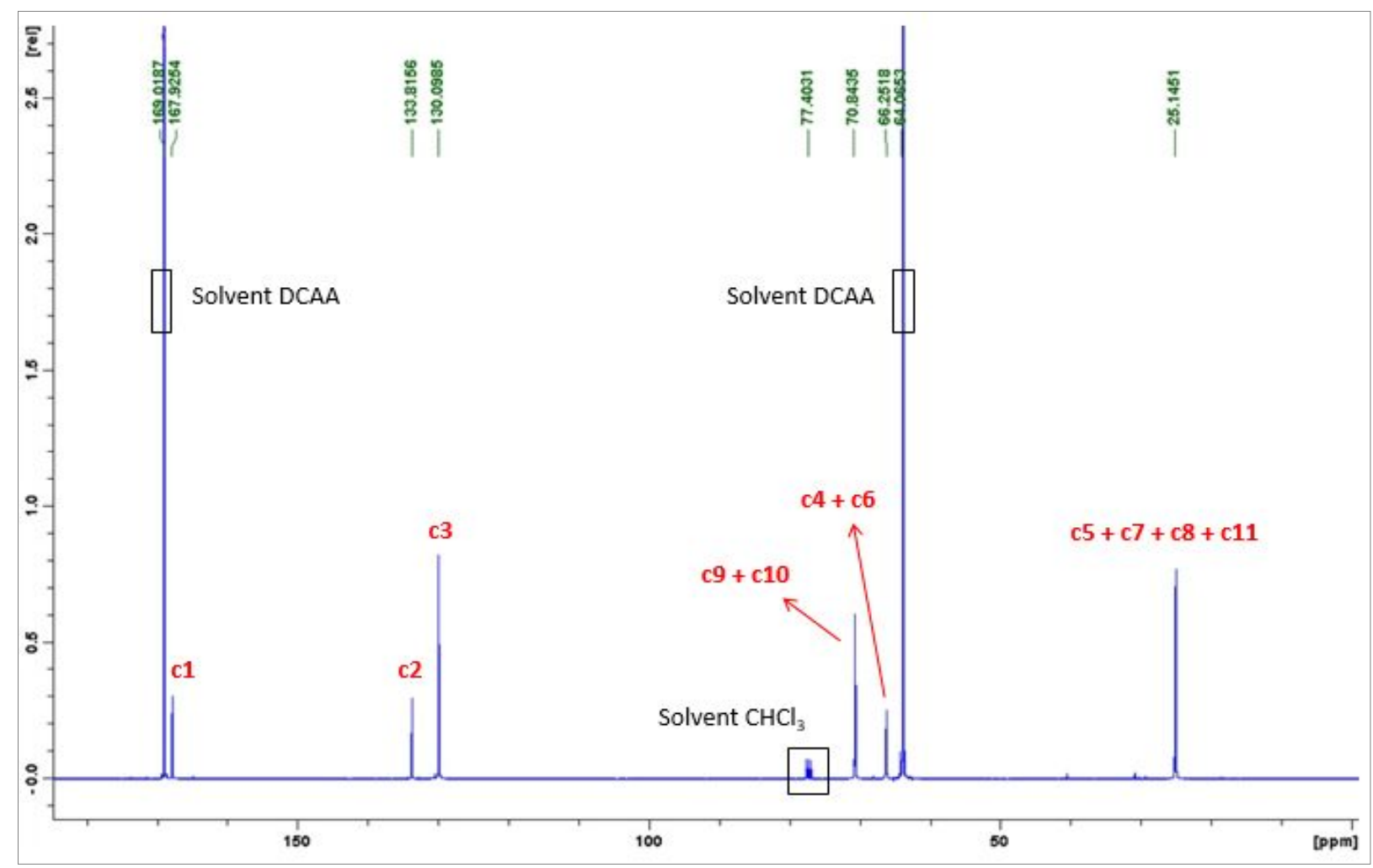

${ }^{13} \mathrm{C}$ NMR Spectrum of COPE in DCAA/CDCl $(80: 20 \mathrm{v} / \mathrm{v})$

Chemical shifts attribution of the COPE signals in DCAA/CDCl $(80: 20 \mathrm{v} / \mathrm{v})$

Shift (ppm)

\section{Structure}

Reference ${ }^{1} \mathrm{H} \quad{ }^{13} \mathrm{C}$

\begin{tabular}{|c|c|c|c|}
\hline \multirow{10}{*}{ (1) } & $\mathrm{c} 1$ & - & 167.93 \\
\hline & $\mathrm{c} 2$ & - & 133.82 \\
\hline & c3 & 8.17 & 130.10 \\
\hline & $\mathrm{c} 4$ & 4.55 & 66.25 \\
\hline & $\mathrm{c} 5$ & 2.07 & 25.15 \\
\hline & c6 & 4.47 & 66.25 \\
\hline & c7 & 1.88 & 25.15 \\
\hline & $\mathrm{c} 8$ & 1.88 & 25.15 \\
\hline & c9 & 3.75 & 70.84 \\
\hline & $\mathrm{c} 10$ & 3.69 & 70.84 \\
\hline
\end{tabular}


$\begin{array}{lll}\mathrm{c} 11 & 1.71 \quad 25.15\end{array}$

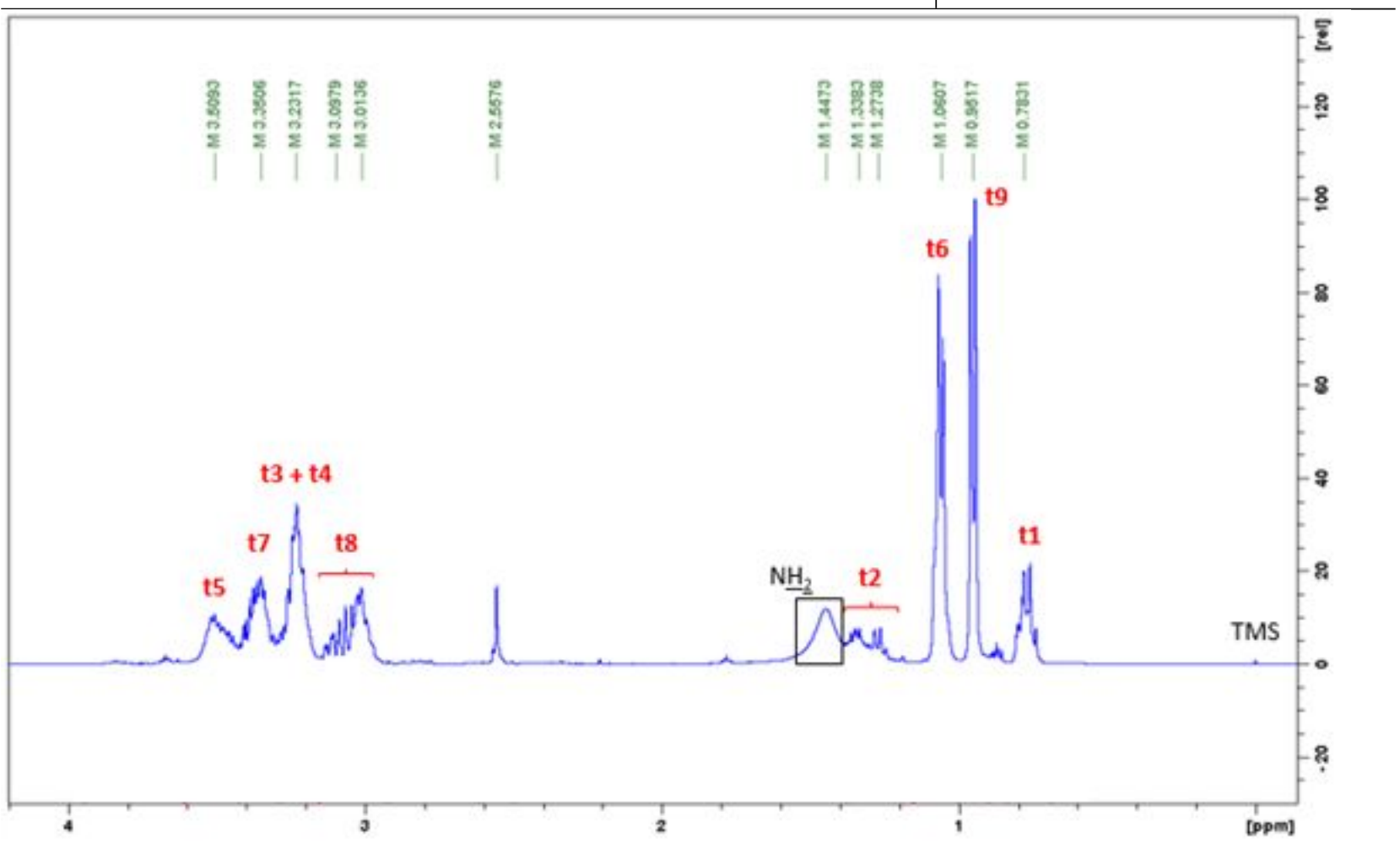

${ }^{1} \mathrm{H}$ NMR Spectrum of T-403 in $\mathrm{CDCl}_{3}$ 


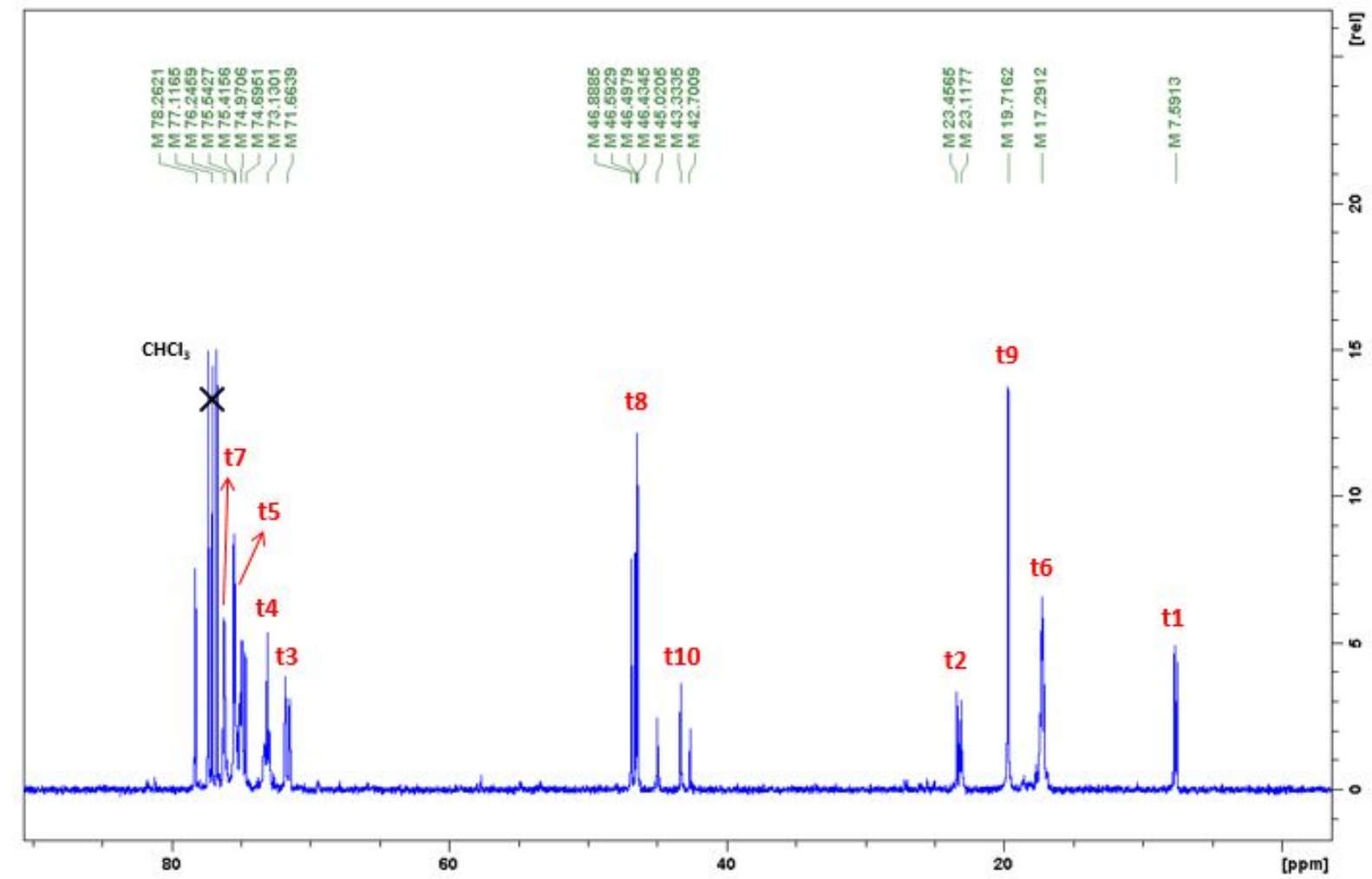

${ }^{13} \mathrm{C}$ NMR Spectrum of T-403 in $\mathrm{CDCl}_{3}$

Chemical shifts attribution of the T-403 signals in $\mathrm{CDCl}_{3}$

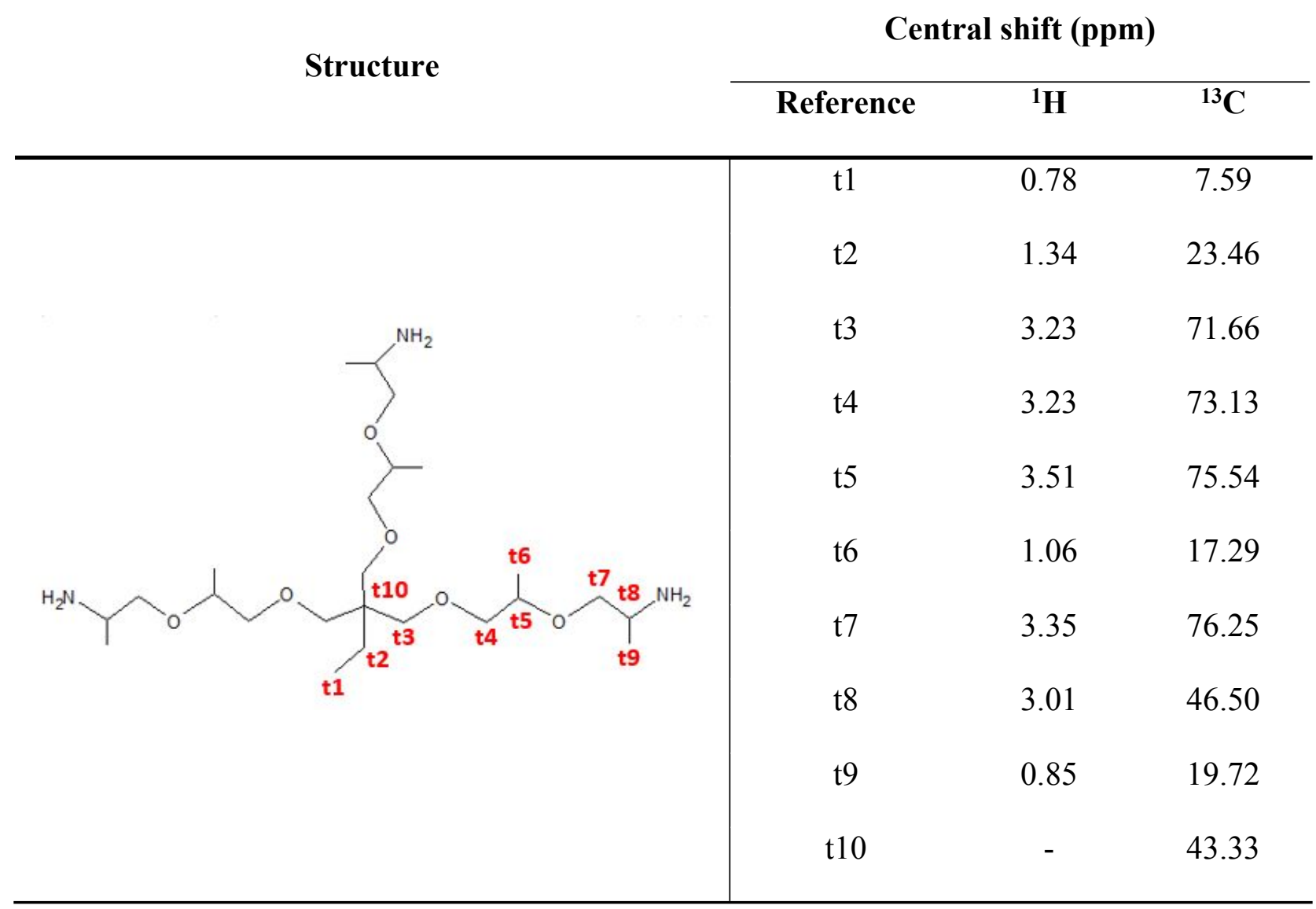




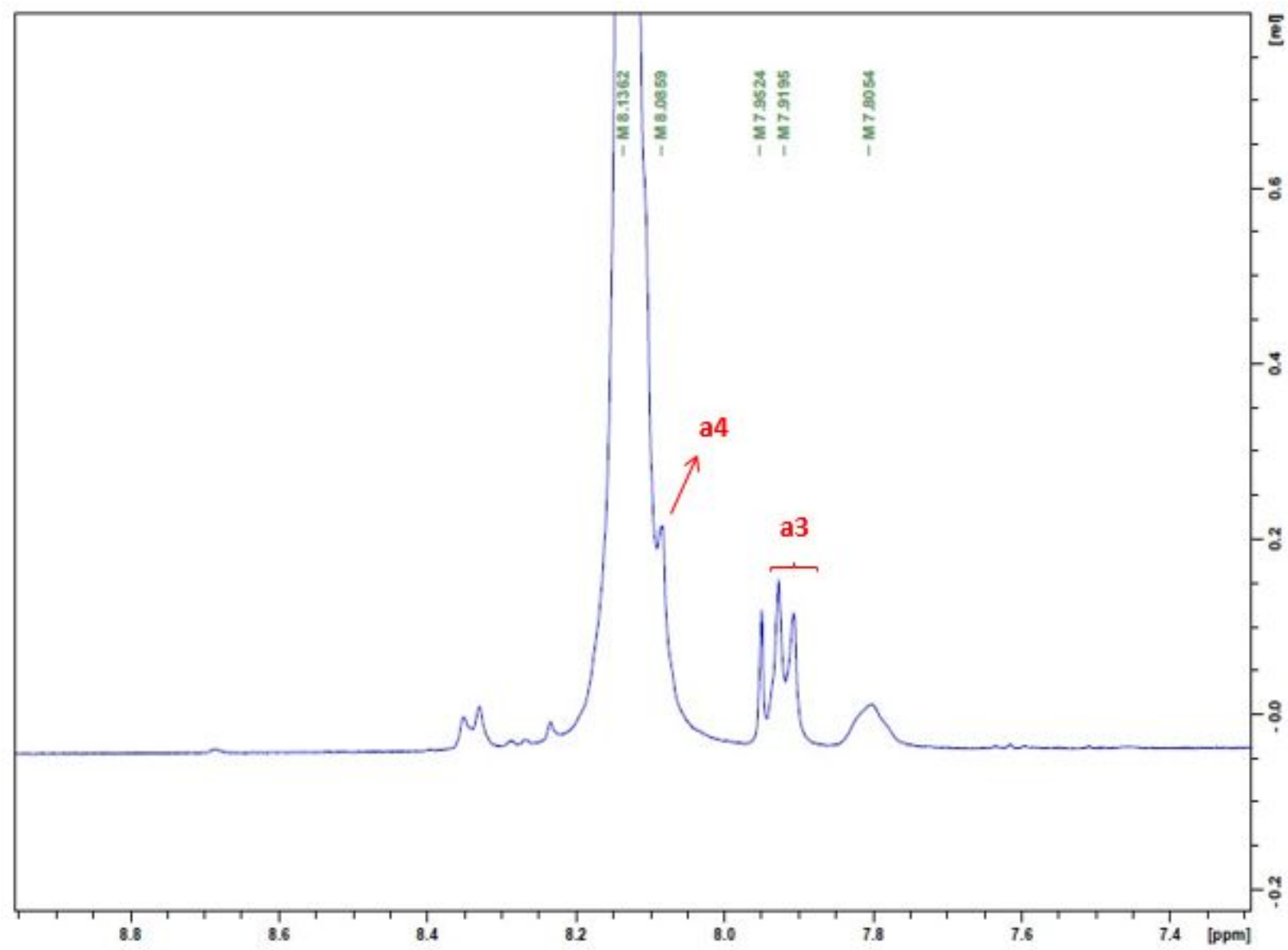

${ }^{1} \mathrm{H}$ NMR Spectrum [7.4-8.9 ppm] of the reactive blend COPE $+10 \% \mathrm{wt} \mathrm{T-403} \mathrm{in} \mathrm{HFIP/CDCl}(80: 20 \mathrm{v} / \mathrm{v})$ 


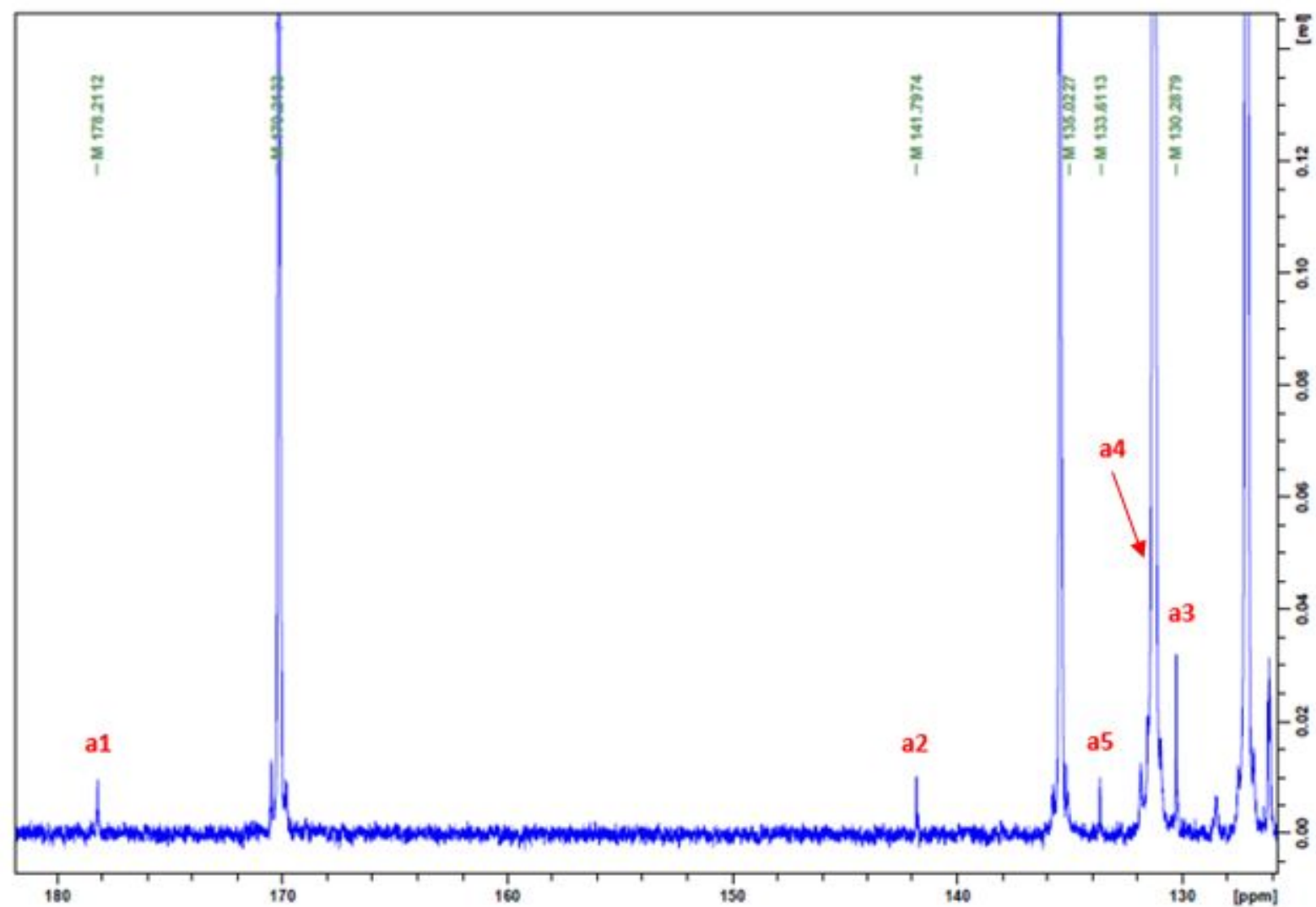

${ }^{13} \mathrm{C}$ NMR Spectrum [125-180 ppm] of the reactive blend COPE $+10 \% \mathrm{wt} \mathrm{T-403} \mathrm{in} \mathrm{HFIP/CDCl}(80: 20 \mathrm{v} / \mathrm{v})$ 


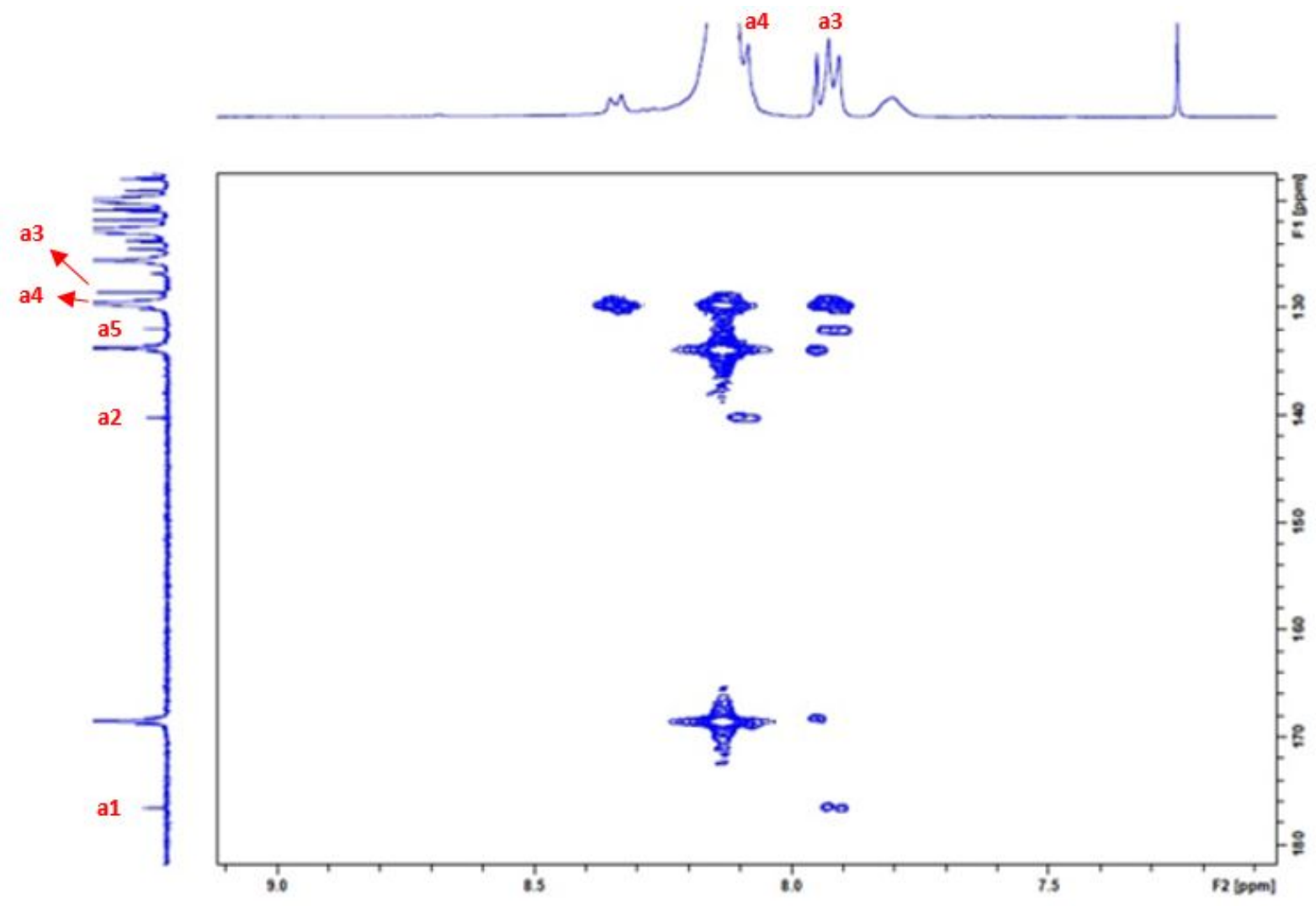

2D HMBC NMR Spectrum of the reactive blend COPE $+10 \% \mathrm{wt} \mathrm{T}-403$ in HFIP/CDCl $3(80: 20 \mathrm{v} / \mathrm{v})$

Chemical shifts attribution of the COPE $+10 \%$ wt T-403 blend signals in $\mathrm{HFIP} / \mathrm{CDCl}_{3}(80: 20 \mathrm{v} / \mathrm{v})$

\begin{tabular}{l|ccc}
\multicolumn{2}{c}{ Structure } & \multicolumn{3}{c}{ Shift (ppm) } \\
\cline { 3 - 4 } & Reference & ${ }^{\mathbf{1}} \mathbf{H}$ & ${ }^{\mathbf{1 3}} \mathbf{C}$ \\
\hline & $\mathrm{a} 1$ & - & 178.21 \\
& $\mathrm{a} 2$ & - & 141.80 \\
& $\mathrm{a} 3$ & 7.92 & 130.29 \\
\hline
\end{tabular}


Figure S2 : VARIATION OF THE COMPLEX VISCOSITY VERSUS FREQUENCY FOR PBT/T-403 blends $\left(\mathrm{T}=220^{\circ} \mathrm{C}\right)$

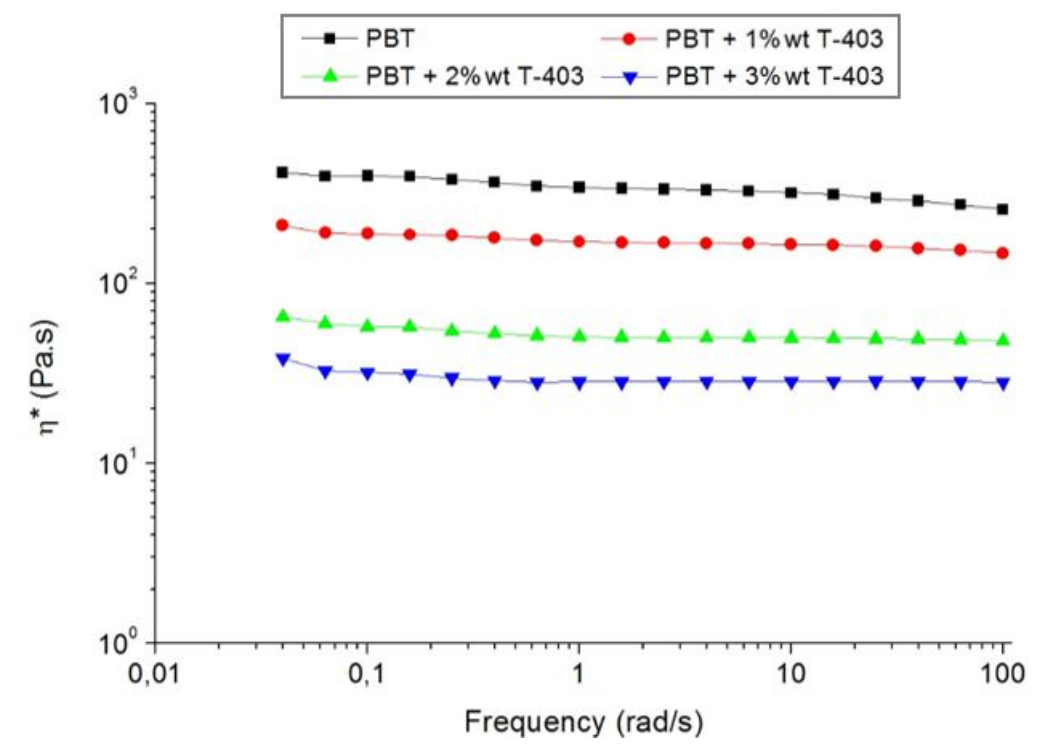

Figure S3: AFM ANALYSIS OF THE COPE/T-403 BLENDS

(a)

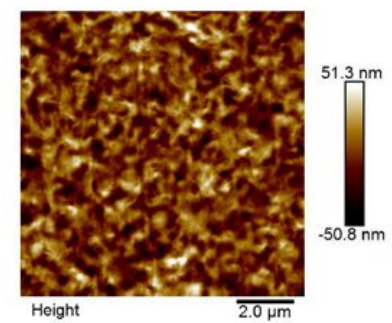

(c)

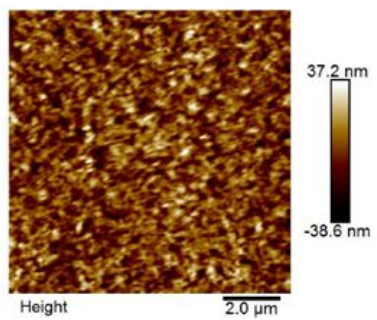

(e)

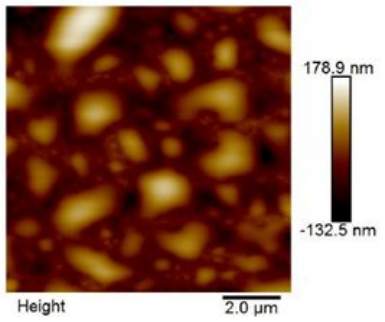

(b)

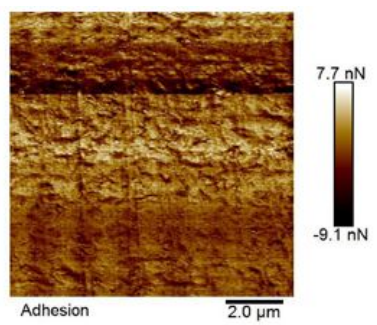

(d)

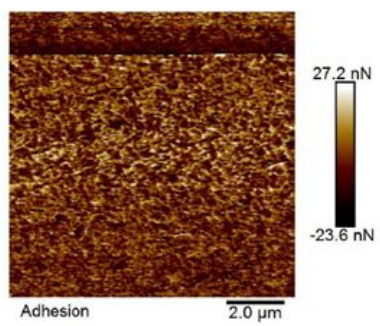

(f)

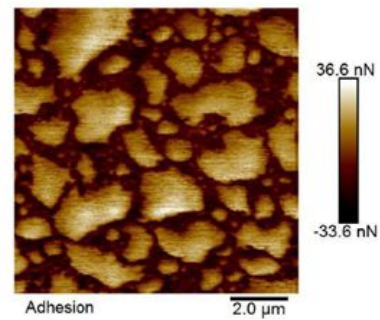

AFM analysis: (a) COPE (height); (b) COPE (adhesion); (c) COPE $+2 \%$ wt T-403 (height); (d) COPE $+2 \% w t$ T-403 (adhesion); (e) COPE $+5 \%$ wt T-403 (height); (f) COPE $+5 \%$ wt T-403 (adhesion) 
Figure S4: COMPARISON OF THE ${ }^{13}$ C NMR SPECTRA OF THE DIFFERENT COPE-JEFFAMINE BLENDS

(d)

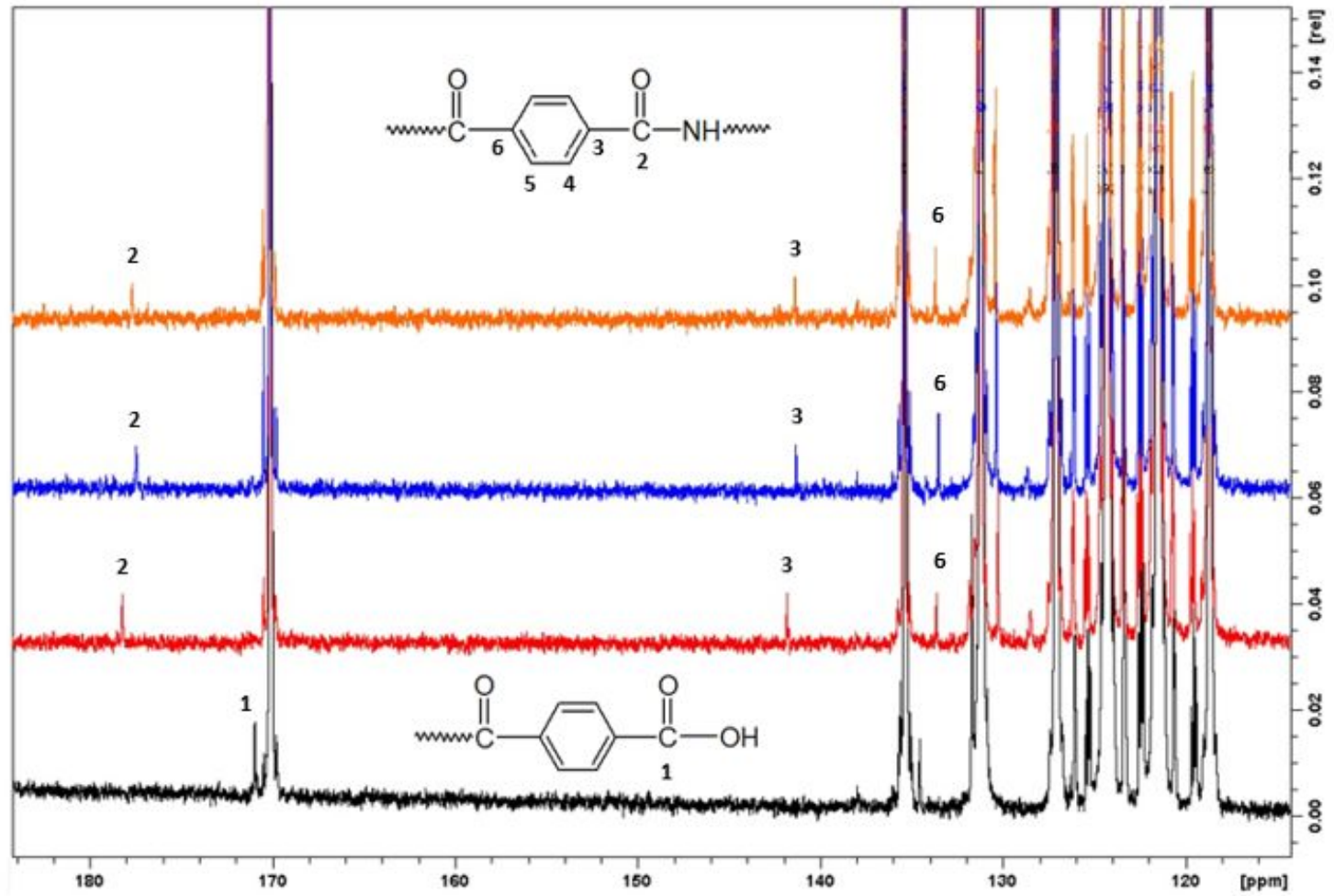

${ }^{13} \mathrm{C}$ NMR Spectra [115-185 ppm] (a) COPE (b) COPE $+10 \%$ wt T-403 (c) COPE $+8 \%$ wt M-600 (d) COPE + $4.5 \%$ wt D-400 in $\mathrm{HFIP} / \mathrm{CDCl}_{3}(80: 20 \mathrm{v} / \mathrm{v})$

\begin{tabular}{|c|c|c|c|c|}
\hline Reactants & Additive composition (\%wt) & {$[\mathbf{C O O H}] \mathbf{C O P E}$} & {$\left[\mathbf{N H}_{2}\right]$ added } & {$\left[\mathbf{N H}_{2}\right] /[\mathbf{C O O H}]$} \\
\hline COPE & 0 & 0.033 & 0 & 0 \\
\hline COPE + M-600 & 8 & 0.031 & 0.140 & 4.52 \\
\hline COPE + D-400 & 4.5 & 0.032 & 0.243 & 7.59 \\
\hline COPE + T-403 & 10 & 0.030 & 0.699 & 23.30 \\
\hline
\end{tabular}


Figure S5: 2D NMR DOSY SPECTRA OF THE COPE/M-600 AND COPE/D-400

\section{BLENDS}

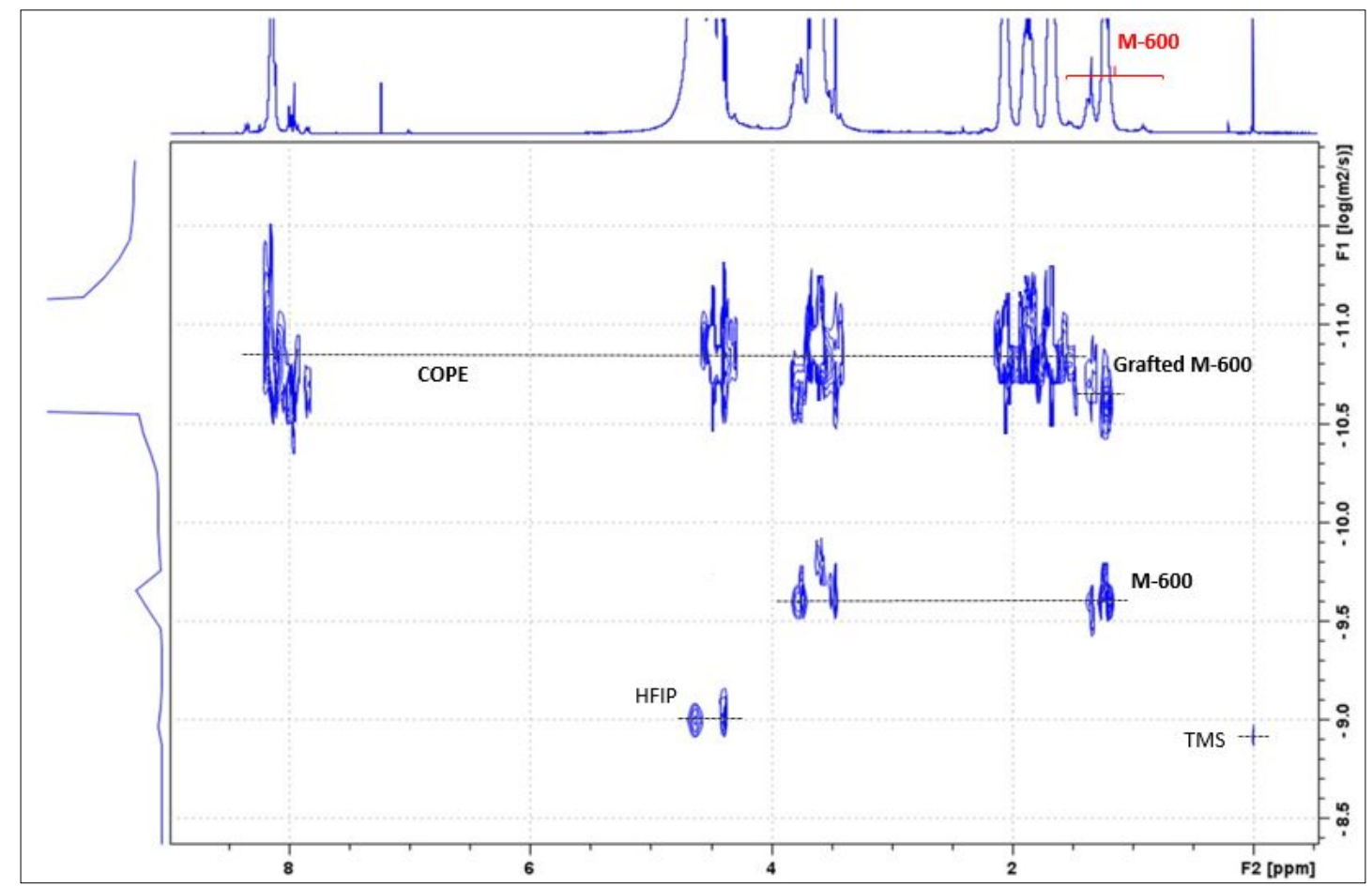

2D NMR DOSY Spectrum of COPE $+8 \%$ wt M-600 blend in HFIP- $\mathrm{d}_{2} / \mathrm{CDCl}_{3}(80: 20 \mathrm{v} / \mathrm{v})$.

For the COPE $+8 \%$ wt M- 600 blend, the diffusion coefficient of the free M-600 was measured at $\mathrm{D}_{\mathrm{M} 1}=2.5 \times 10^{-10} \mathrm{~m}^{2} \cdot \mathrm{s}^{-1}$, while the diffusion coefficient of the grafted M-600 was measured at $\mathrm{D}_{\mathrm{M} 2}=2.5 \times 10^{-11} \mathrm{~m}^{2} . \mathrm{s}^{-1}$, corresponding to the range of NMR diffusion coefficient for the COPE. 


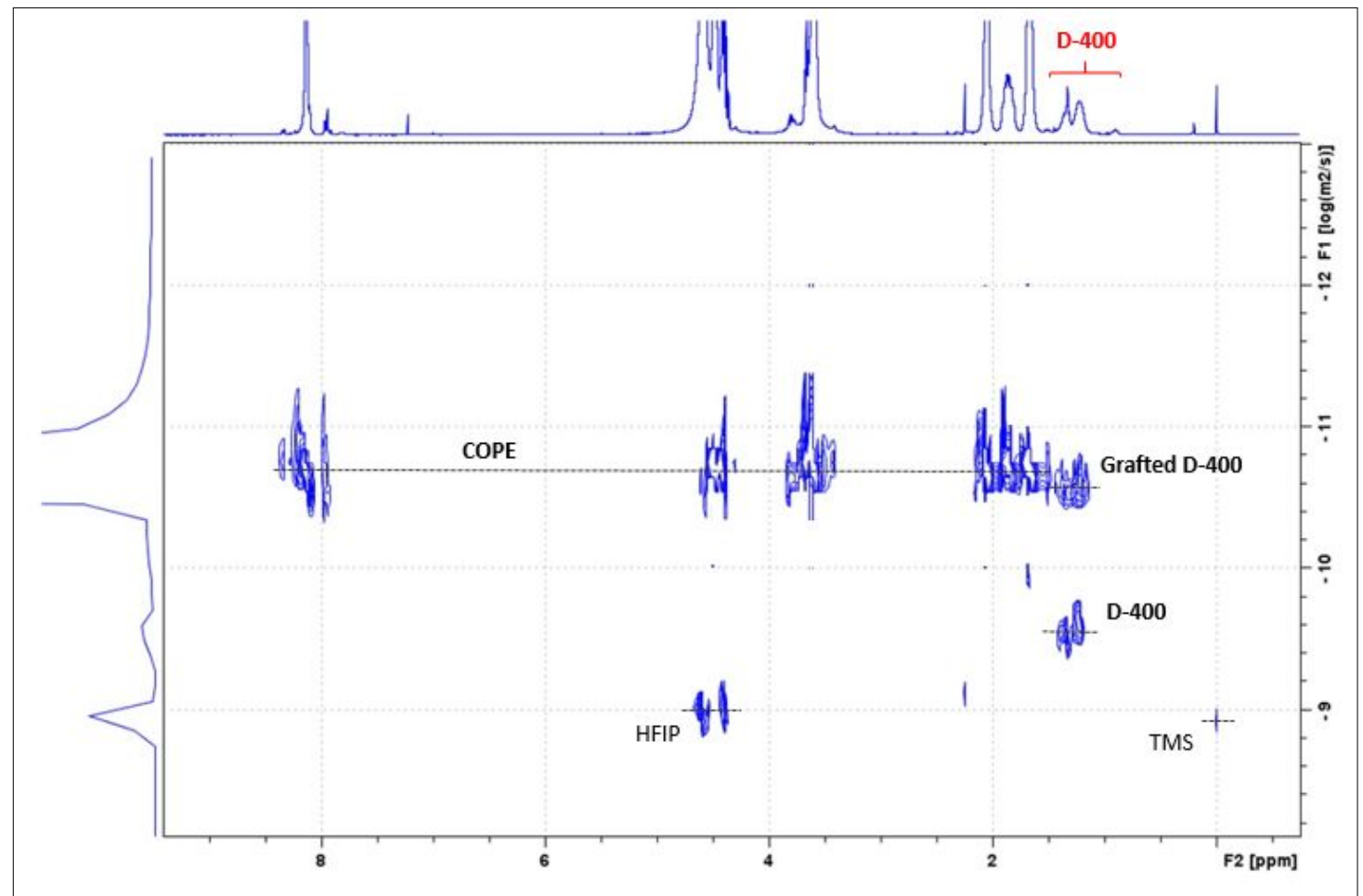

2D NMR DOSY Spectrum of COPE $+4.5 \%$ wt D-400 blend in HFIP- $\mathrm{d}_{2} / \mathrm{CDCl}_{3}(80: 20 \mathrm{v} / \mathrm{v})$.

For the COPE $+4.5 \%$ D-400 blend, the diffusion coefficient of the free D-400 was measured at $\mathrm{D}_{\mathrm{D} 1}=2.7 \times 10^{-10} \mathrm{~m}^{2} \cdot \mathrm{s}^{-1}$, while the diffusion coefficient of the grafted D-400 was measured at $\mathrm{D}_{\mathrm{D} 2}=2.9 \times 10^{-11} \mathrm{~m}^{2} \cdot \mathrm{s}^{-1}$ which is in the range of the diffusion coefficient of the COPE.

As observed for the COPE/T-403 systems, two different NMR correlation signals were witnessed for the Jeffamines, proving that a reaction of the M-600 and the D-400 on the COPE occurred during the blend.

It will be noted that the three Jeffamines (M-600, D-400 and T-403) presenting molar masses from 400 to 600 g.mol ${ }^{-1}$ exhibit diffusion coefficients of the same order of magnitude. 